\title{
Exercise-induced changes in basal ganglia volume and their relation to cognitive performance
}

\author{
Becker L', Kutz DF², Voelcker-Rehage $\mathrm{C}^{1 *}$
}

'Institute of Human Movement Science and Health, Sports Psychology, Technische Universität Chemnitz, Thüringer Weg 11,09126 Chemnitz, Germany ${ }^{2}$ Institute of Human Movement Science and Health, Theory and Practice of Sports, Technische Universität Chemnitz, Thüringer Weg 11 , 09126 Chemnitz, Germany

\section{Article Info}

\section{Article Notes}

Received: June 06, 2016

Accepted: August 08, 2016

\section{*Correspondence:}

Dr. Claudia Voelcker-Rehage

Institute of Human Movement Science and Health,

Sports Psychology, Technische Universität Chemnitz,

Thüringer Weg 11, 09126 Chemnitz, Germany

E-mail: claudia.voelcker-rehage@hsw.tu-chemnitz.de

(C) 2016 Voelcker-Rehage C. This article is distributed under the terms of the Creative Commons Attribution 4.0 International License

\section{Keywords}

Basal ganglia

Grey matter

Cognition

Physical activity

Cardiovascular fitness

Motor fitness

Children

Older adults

\section{Introduction}

Physical activity, especially cardiovascular fitness training, has been shown to enhance cognitive performance and to counteract agerelated cognitive decline $e^{1-5}$. Furthermore, regular physical activity has been demonstrated to diminish age-related volume-shrinkage in several brain regions particularly in the prefrontal cortex and hippocampus ${ }^{6-10}$. In the same vein, physical activity and high levels of cardiovascular fitness seem to enhance neurocognition during childhood ${ }^{11-13}$. In this context, the basal ganglia and its components, the caudate nucleus, the putamen and the globus pallidus, are of special interest as animal research indicates that exercise also seems to influence the molecular architecture and the metabolic capacity of the basal ganglia ${ }^{14,15}$. Besides their fundamental role in motor execution ${ }^{16}$, the basal ganglia are also involved in many cognitive functions like mental flexibility ${ }^{17}$, task-switching ability ${ }^{18}$ and cognitive control ${ }^{19}$. Furthermore, age-related disorders like Parkinson's disease are related to a decline in the dopamine circuits of the basal ganglia ${ }^{20,21}$.

The striatum is the input nucleus of the basal ganglia and is composed of caudate nucleus and putamen. The pars interna of the globus pallidus is (together with the substantia nigra pars reticulata) the output region of the basal ganglia and conveys information from the striatum to the thalamus and back to the frontal areas ${ }^{22}$. The striatum, which is essential for cognitive flexibility and attentional control, shows an increase during childhood and adolescence ${ }^{23,24}$ and a particularly rapid and early age-related change ${ }^{9,25}$ in older adults. Furthermore, the described cognitive functions are essential for academic success of children and young adults. Thus, it is of particular interest to find appropriate interventions that could mitigate both the volume-shrinkage and the (presumably) related cognitive decline in older adults and/or that could support academic success in children. In this review, we will summarize research that investigated whether physical activity has the potential to be such an intervention. First, we will show that neuroplasticity in the basal ganglia is possible in principle. Second, we will report studies where the relationship between physical fitness level and volume of the basal ganglia and its relation to cognitive performance were investigated. Besides crosssectional studies, we will report studies that investigated exerciseinduced changes in the volume of the basal ganglia and related changes in cognitive performance after long-term fitness interventions. 


\section{Neuroplasticity of basal ganglia volumes}

The basal ganglia are, prospectively, positively influenced by physical activity because animal research indicated that cardiovascular exercise does not only seem to influence angiogenesis, synaptogenesis and the release of growth hormones in motor cortex ${ }^{26}$, cerebellum ${ }^{27}$ and hippocampus 28,29 , but also in the basal ganglia ${ }^{15}$. Furthermore, the striatum is the second region - besides the hippocampus - where neurogenesis in humans has been proven ${ }^{30,31}$. Plasticity of basal ganglia has been proven in motor learning studies. It has been shown that motor learning can lead to changes in basal ganglia volumes after minimal training. For example, Hamzei and colleagues ${ }^{32}$ found that young adults (mean age 23.8 years) showed an increase in the volume of the right ventral striatum after three days of a 30-minute training of writing their signature with the non-dominant hand. Taubert and colleagues ${ }^{33}$ found structural changes in the right putamen of young adults ( $25.9 \pm 2.8$ years) after six weeks of a dynamic wholebody balancing training (1 training session per week; 45 minutes each). Thus, neuroplasticity in the basal ganglia is possible in general. However, from these learning studies it cannot be determined whether structural changes can also be induced by cardiovascular training and other forms of exercise (as opposed to motor skill learning), and whether changes in the gray matter lead to additional changes in cognitive performance. Furthermore, it cannot be concluded whether the reported effects can be generalized to other age groups.

Relations between physical activity, volume of basal ganglia and cognitive performance

So far, only a few human studies have investigated the association between regular physical activity and the volume of basal ganglia and their relation to cognitive performance. These studies differ with regard to the sample (children versus adult subjects), study design (cross-sectional versus interventional studies), type of exercise (cardiovascular versus coordinative exercise) and outcome variables (basal ganglia volume and additionally cognitive performance). An overview about the reported studies is provided in Table 1 . First, we will give an overview of cross-sectional studies that compared volumes of basal ganglia between groups with different levels of physical fitness (e.g., high-fit vs. low-fit) in relation to their cognitive performance. Second, interventional studies that investigated the impact of fitness interventions on cognitive performance and on the volume of basal ganglia will be reported.

\section{Cross-sectional studies}

Chaddock and colleagues ${ }^{34}$ found that higher cardiovascular fitness levels were associated with higher volumes of the left caudate nucleus, the bilateral putamen and the bilateral globus pallidus in preadolescent children $(\mathrm{N}=55,10.0 \pm 0.6$ years; Region of Interest (ROI) analysis, of the striatum and globus pallidus, FMRIB's Software Library (FSL)). Additionally, the volumes of the putamen and the globus pallidus positively correlated with performance in a Flanker task. The Flanker task is a selective attention paradigm, that is often employed to examine cognitive control performance (especially the aspect of cognitive interference control) ${ }^{35}$. The classical task is for example to respond to an arrow's direction that is either congruent or incongruent to the direction of neighboring arrows. Chaddock and colleagues ${ }^{34}$ concluded that the association between the volume of the dorsal striatum and the cognitive control performance supports the assumption that these nuclei are also involved in motor integration and response resolution. In a follow-up study, Chaddock and colleagues ${ }^{36}$ found that approximately one year later, the high-fit children still showed superior performance in the Flanker task compared to the low-fit children. The authors attributed these better cognitive performances to the previously measured higher fitness levels and to the greater volumes of the putamen and globus pallidus measured one year earlier.

For healthy young adults ( $\mathrm{N}=33,23.9 \pm 3.4$ years), Peters and colleagues ${ }^{37}$ found that higher levels of cardiovascular fitness were related to larger volumes of the basal ganglia (whole brain analysis, voxel-based morphometry (VBM)). No differences in memory performance were found between the groups. The authors did not investigate other cognitive functions (like cognitive control performance) in that the basal ganglia might be more involved.

For healthy older adults $(\mathrm{N}=179,66.6 \pm 5.6$ years $)$, Verstynen and colleagues ${ }^{38}$ found (by means of the same analysis tool as Chaddock and colleagues ${ }^{34,36}$ ) that higher cardiovascular fitness levels correlated positively with taskswitching performance and thus with cognitive flexibility. Furthermore, the volumes of the caudate nucleus, the putamen and the globus pallidus were positively related to task-switching performance as well. No effects were found for the Flanker task. A mediation analysis revealed that the volume of the caudate nucleus partially explained the relationship between the cardiovascular fitness level and the task-switching performance, but no mediating effect between the volume of the putamen or the volume of the globus pallidus and the task-switching performance was found.

In most studies, only the association of cardiovascular fitness level (trained by exercises like walking, swimming, bicycling) on the volume of basal ganglia and on cognitive performance was examined. Motor fitness level, comprising coordinative abilities such as balance, eye-hand coordination, and arm-leg coordination, can be associated with cognitive performance as well ${ }^{5}$. Niemann and 


\begin{tabular}{|c|c|c|c|c|c|}
\hline Authors & Fitness type & $\begin{array}{l}\text { Group } \\
\text { (mean age in years } \pm S D \text { ) }\end{array}$ & $\mathbf{N}$ & $\begin{array}{l}\text { Cognitive } \\
\text { tests }\end{array}$ & Main findings \\
\hline \multicolumn{6}{|l|}{ Cross-sectional } \\
\hline $\begin{array}{l}\text { Chaddock et al. } \\
(2010)\end{array}$ & $\begin{array}{l}\text { Cardiovascular } \\
\text { fitness }\end{array}$ & Children $(10.0 \pm 0.6)$ & $\begin{array}{l}55 \text { ( } 25 \text { high-fit, } 30 \\
\text { low-fit) }\end{array}$ & $\mathrm{FT}$ & $\begin{array}{l}\text { Relationship between basal ganglia volume and } \\
\text { interference in the FT for the putamen (left: } r \\
=-.33, p=.01 \text {; right: } r=-.247, p=.06 \text { ) and the } \\
\text { globus pallidus (left: } r=-.201, p=.05 \text {; right: } r= \\
-.35, p=.009 \text { ). }\end{array}$ \\
\hline $\begin{array}{l}\text { Chaddock et al. } \\
(2012)\end{array}$ & $\begin{array}{l}\text { Cardiovascular } \\
\text { fitness }\end{array}$ & Children $(10.1 \pm 0.6)$ & $\begin{array}{l}32 \text { (14 high-fit, } 18 \\
\text { low-fit) }\end{array}$ & $\mathrm{FT}$ & $\begin{array}{l}\text { Relationship between basal ganglia volume } \\
\text { (measured } 1 \text { year earlier) and reaction time in } \\
\text { the FT (measured in the follow-up session) for } \\
\text { the putamen }(r=-.37-. .43, p<.05 \text { ) and the } \\
\text { globus pallidus ( } r=-.37--.49, p<.05) .\end{array}$ \\
\hline $\begin{array}{l}\text { Peters et al. } \\
\text { (2009) }\end{array}$ & $\begin{array}{l}\text { Cardiovascular } \\
\text { fitness }\end{array}$ & Young adults $(23.9 \pm 3.4)$ & $\begin{array}{l}33 \text { ( } 21 \text { high-fit, } 12 \\
\text { low-fit) }\end{array}$ & MT & $\begin{array}{l}\text { Volumes of the right globus pallidus and the } \\
\text { bilateral putamen were larger for the high-fit } \\
\text { than for the low-fit participants }(p<.001) \text {. } \\
\text { No differences in memory performance were } \\
\text { found between participants with different } \\
\text { fitness levels. }\end{array}$ \\
\hline $\begin{array}{l}\text { Verstynen et al. } \\
(2012)\end{array}$ & $\begin{array}{l}\text { Cardiovascular } \\
\text { fitness }\end{array}$ & Adults $(66.6 \pm 5.6)$ & 179 & TS, FT & $\begin{array}{l}\text { Mediation pathway between fitness level } \\
\text { and accuracy in the TS through volume of the } \\
\text { caudate nucleus ( } a b=.0037, p=.003, R^{2}= \\
.1661 \text { ). } \\
\text { No effects for the FT. }\end{array}$ \\
\hline $\begin{array}{l}\text { Niemann et al. } \\
\text { (2014) }\end{array}$ & $\begin{array}{l}\text { Cardiovascular } \\
\text { and motor } \\
\text { fitness }\end{array}$ & Adults $(68.5 \pm 3.6)$ & 70 & FT, VS & $\begin{array}{l}\text { No relationship between cognitive performance, } \\
\text { CF level and the volume of the basal ganglia. } \\
\text { The volume of the whole basal ganglia volume } \\
\text { partially moderated the relationship between } \\
\text { MF and cognitive performance for participants } \\
\text { with small basal ganglia volumes in the FT ( } p< \\
.10) \text {. }\end{array}$ \\
\hline \multicolumn{6}{|l|}{ Interventional } \\
\hline $\begin{array}{l}\text { Erickson et al. } \\
\text { (2011) }\end{array}$ & $\begin{array}{l}\text { Cardiovascular } \\
\text { fitness }\end{array}$ & Adults $(67.6 \pm 5.8)$ & $\begin{array}{l}120(60 \\
\text { intervention, } 60 \\
\text { control group) }\end{array}$ & MT & $\begin{array}{l}\text { No change of the volume of the caudate nucleus } \\
\text { in the intervention group. } \\
\text { No relationship between caudate nucleus } \\
\text { volume and MT performance. }\end{array}$ \\
\hline $\begin{array}{l}\text { Niemann et al. } \\
\text { (2014) }\end{array}$ & $\begin{array}{l}\text { Cardiovascular } \\
\text { and motor } \\
\text { fitness }\end{array}$ & $\begin{array}{l}\text { Adults (cardiovascular } \\
\text { fitness: } 67.7 \pm 2.8 ; \text { motor } \\
\text { fitness: } 69.5 \pm 4.7 \\
\text { control group: } 69.6 \pm 3.4 \text { ) }\end{array}$ & $\begin{array}{l}36(13 \\
\text { cardiovascular } \\
\text { fitness intervention, } \\
14 \text { motor fitness } \\
\text { intervention, } 9 \\
\text { control group) }\end{array}$ & FT, VS & $\begin{array}{l}\text { A marginally significant effect }(p=.065) \text { of the } \\
\text { intervention on the volume of the basal ganglia } \\
\text { was found for CF training. } \\
\text { The MF training increased the volumes of both } \\
\text { the caudate nucleus ( } p=.05 \text { ) and the globus } \\
\text { pallidus ( } p=.022) \text {. } \\
\text { Accuracy in the FT was positively associated } \\
\text { with MF training }\left(p=.019, p^{2}=.45\right) \text {, but not } \\
\text { with CF training. }\end{array}$ \\
\hline
\end{tabular}

Note: FT: Flanker task; TS: task switching task; MT: memory task; VS: visual search task; $\mathrm{CF}=$ cardiovascular fitness; $\mathrm{MF}=$ motor fitness.

Table 1. Human studies that investigated both the basal ganglia volumes and the cognitive performance.

colleagues $^{39}$ showed (ROI analysis of basal ganglia, manual morphometry) that the total volume of the basal ganglia and the volumes of the putamen and the globus pallidus partially explained the relationship between motor fitness level (but not cardiovascular fitness level) and cognitive control performance in a Flanker task in healthy older adults $(\mathrm{N}=70,68.5 \pm 3.6$ years). In participants with low basal ganglia volume, the motor fitness level was positively related to cognitive control performance. However, this relationship was not found in participants with large volumes of the basal ganglia. For a Visual Search task (as a measure of perceptual speed), the motor fitness level predicted cognitive performance, but no association with the volume of basal ganglia was found.

\section{Interventional studies}

For healthy older adults ( $\mathrm{N}=60,67.6 \pm 5.8$ years), Erickson and colleagues ${ }^{40}$ found no change in the volume of the caudate nucleus in an intervention group that participated in a 12-month cardiovascular training (ROI 
analysis of the caudate nucleus, FSL). In addition, no correlation between the fitness level and the volume of the caudate nucleus was found. Interestingly, the authors found a decrease in the volume of the caudate nucleus in their stretching exercise control group across one year. This might indicate a general age-related decline in the caudate nucleus volume in the control group and preservation (i.e., a non-decline - probably due to the cardiovascular exercise) in the intervention group. Niemann and colleagues ${ }^{39}$ investigated healthy older adults in both a one-year cardiovascular intervention $(\mathrm{N}=13,67.7 \pm 2.8$ years $)$ and a one-year motor fitness level intervention (a coordination training, $\mathrm{N}=14,69.5 \pm 4.7$ years). They found that the coordination training increased the volumes of both the caudate nucleus and the globus pallidus (ROI analysis of basal ganglia, manual morphometry). The authors attributed this effect to the constant demand on adapting to new tasks in the coordination training, involving the same regions as in early stages of motor learning (e.g., the caudate nucleus ${ }^{41}$ and the globus pallidus ${ }^{22}$ ). For the cardiovascular intervention, only a marginally significant effect $(p=.065)$ of the intervention on the volume of the basal ganglia was found, indicating an volume increase during the first six months of the intervention and a decrease during the second half of the intervention. Cognitive control performance was positively associated with coordination training as well, but not with cardiovascular training. However, there was no direct association between the change in the volume of the basal ganglia after motor fitness intervention and the increase in cognitive performance.

\section{Discussion}

Although the impact of physical activity on the volume of basal ganglia and its relation to cognitive performance has been sparsely examined in humans, there is some evidence for a direct relation between these factors in human research. Correlations were found for both cardiovascular and motor fitness level interventions. However, the reported effects are divergent.

For children, only one study (and a one year Follow-up study) investigated the relation between cardiovascular fitness and the volume of the basal ganglia and cognitive performance. The authors found an effect for the putamen and the globus pallidus $\mathrm{s}^{34,35}$.

For older adults, the volume of the caudate nucleus explained the relationship between their cardiovascular fitness level and their cognitive performance in a crosssectional data $\operatorname{set}^{38}$. Considering the high relevance of the caudate nucleus for cognitive flexibility, a high fitness level (correlating with the volume of the caudate nucleus) might prevent the age-related decline in mental flexibility performance. Physical activity has therefore the potential to increase the quality of life and the everyday functioning of older adults.
In contrast to the cross-sectional results, neither Erickson and colleagues ${ }^{40}$ nor Niemann and colleagues ${ }^{39}$ (in the second 6 months of their intervention) found by means of interventional designs that cardiovascular exercise (walking training) has any effect on the volume of basal ganglia (although data of Erickson and colleagues ${ }^{40}$ might indicate reduced age-related decline due to regular cardiovascular activity).

While learning the appropriate walking technique might be highly processed with inclusion of the basal ganglia during the first half of the intervention of the study by Niemann and colleagues ${ }^{39}$, the adaptation of this now highly automated movement might be increasingly processed outside of the basal ganglia (e.g., in the cerebellum ${ }^{42}$ ) during the second half of the intervention.

Besides cardiovascular exercise, coordination training or motor fitness level training seem to be a promising means to increase basal ganglia volume. The total volume of the basal ganglia was related to coordinative aspects of fitness and partially explained the cognitive performance (for subjects with low basal ganglia volumes only ${ }^{39}$. Furthermore, after a one-year motor fitness level intervention, the participants showed greater volumes of the caudate nucleus and the globus pallidus. Changes induced by coordination training might be related to changes in information processing ${ }^{43}$ similar to early stages of motor learning. The exercise requirement might be the reason for the volume increase found in the caudate and the globus pallidus for subjects that attended the coordination training. Further research is needed to show if the same effect can be demonstrated for other populations (e.g., children, young adults, cognitive impaired participants) or for other forms of fitness training (e.g., strength training).

In the studies reported so far, if effects were found, the correlations between the volumes of the basal ganglia and the cognitive performances were always positive. This means that the impact of physical activity on cognitive performance corresponds to higher volumes of the basal ganglia in the reported cases. Different types of exercise and fitness seem to influence basal ganglia volume, but further research is needed to investigate whether the effects are induced by the same or by different (additive or sole) mechanisms. Furthermore, volume changes seem to occur on different time lines ${ }^{32,33,44}$.

In this line, results of studies that compared volumes of the basal ganglia between professional athletes and nonathletes are less clear. For the total striatum, larger volumes were found in skilled young basketball players $(20.3 \pm 1.1$ years) than in a control group ${ }^{45}$. Contradictory, in the left putamen of young professional ballet dancers $(24.3 \pm 5.5$ years $)^{46}$, in the putamen and the globus pallidus of middleaged highly skilled golfers $(30.9 \pm 6.2 \text { years })^{47}$ and in the left caudate nucleus of professional adolescent diving players 
(14.6 \pm 1.7 years $)^{48}$, smaller volumes than in control groups were found. Thus, the direction of change in the volume of the basal ganglia seems to differ between different sports, possibly attributable to different sport-specific requirements (e.g., recall of well learned, self-timed, highly automated movements versus instantaneous reaction to highly contextual, gameplay related contingencies). It is not yet clear if and how all induced changes in basal ganglia volume directly or indirectly result in changes in cognitive performance and whether certain mechanisms need to be induced to have translational effects from motor activity to cognitive performance.

The causes of the changes in the volumes of the basal ganglia are still unclear. Underlying biological mechanisms identified in animal research are characterized by synaptic changes including synaptogenesis, dendritic, astrocytic and glia cell hypertrophy ${ }^{49}$. These motor-demanding, exercise-based morphological brain changes might result in increasing or persistently larger volumes of the basal ganglia. However, methods used in human studies do not relate in a straightforward way to the underlying neuronal densities that can be assessed in animal research. In animal studies, results are based on invasive techniques like microscopy of brain slices. Tissue properties like cell density cell size or myelination might be possible underlying mechanisms of increased basal ganglia volume ${ }^{44}$ but cannot be derived from the results of grey matter analysis in humans. Further research is necessary to clarify this.

Because of the small number of studies and the different investigated time lines, the reasons for the divergent effects especially between the cross-sectional and the interventional studies are not yet clear. Reasons might be different tools used for statistical analyses as well as for basal ganglia volume determination (semi-automated methods vs. manual morphometry) ${ }^{5,50}$, the small sample sizes in the interventional studies or differences in the absolute fitness levels between the participants. Thus, further research is needed to replicate the reported effects.

To conclude, physical activity, especially motor fitness level training, might be a promising tool that leads to structural changes in the basal ganglia. This might have the potential to diminish the cognitive decline in older adults and to support the academic success in children and young adults.

\section{Acknowledgement}

The publication costs of this article were funded by the German Research Foundation/DFG and the Technische Universität Chemnitz in the funding programme Open Access Publishing.

\section{References}

1. Yaffe K, Barnes D, Nevitt M, Lui LY, Covinsky K. A prospective study of physical activity and cognitive decline in elderly women: women who walk. Arch Intern Med. 2001; 161: 1703-1708.
2. Colcombe S, Kramer AF. Fitness effects on the cognitive function of older adults: a meta-analytic study. Psychol. Sci. 2003; 14: 125-130.

3. Etnier JL, Nowell PM, Landers DM, Sibley BA. A meta-regression to examine the relationship between aerobic fitness and cognitive performance. Brain Res Rev. 2006; 52(1): 119-130.

4. Best JR. Effects of physical activity on children's executive function: contributions of experimental research on aerobic exercise. Dev Rev. 2010; 30: 331-351.

5. Voelcker-Rehage C, Niemann C. Structural and functional brain changes related to different types of physical activity across the life span. Neurosci Biobehav Rev. 2013; 37(9 Pt B): 2268-2295.

6. Colcombe SJ, Erickson KI, Scalf PE, Kim JS, Prakash R, McAuley E, Elavsky S, Marquez DX, Hu L, Kramer AF. Aerobic exercise training increases brain volume in aging humans. J. Gerontol. A Biol. Sci. Med. Sci. 2006; 61: 1166-1170.

7. Kramer AF, Erickson KI, Colcombe SJ. Exercise, cognition, and the aging brain. J Appl Physiol. 2006; 101(4): 1237-1242.

8. Park DC, Reuter-Lorenz PA. The adaptive brain: aging and neurocognitive scaffolding. Annu Rev Psychol. 2009; 60: 173-196.

9. Torres ER, Strack EF, Fernandez CE, Tumey TA, Hitchcock ME. Physical activity and white matter hyperintensities: A systematic review of quantitative studies. Prev Med Reports, 2015; 2: 319-325.

10. Ruscheweyh R, Willemer C, Kruger K, Duning T, Warnecke T, Sommer J, Flöel A. Physical activity and memory functions: an interventional study. Neurobiol Aging. 2011; 32(7): 1304-1319.

11. Sibley BA, Etnier JL. The relationship between physical activity and cognition in children: a meta-analysis. Pediatr Exerc Sci. 2003; 15: 243-256.

12. Hillman CH, Erickson KI, Kramer AF. Be smart, exercise your heart: exercise effects on brain and cognition. Nature Rev Neurosci. 2008. 9: 58-65.

13. Davis CL, Tomporowski PD, McDowell JE, Austin BP, Miller PH, Yanasak NE, Allison JD, Naglieri JA, 2011. Exercise improves executive function and achievement and alters brain activation in overweight children: a randomized, controlled trial. Health Psychol. 2011; 30: 91-98.

14. McCloskey DP, Adamo, DS Anderson BJ. Exercise increases metabolic capacity in the motor cortex and striatum, but not in the hippocampus. Brain Research. 2001; 891(1): 168-175.

15. Ding YH, Li J, Luan X, Ding YH, Lai Q Rafols JA, Phillis JW, Clark JC, Diaz FG. Exercise pre-conditioning reduces brain damage in ischemic rats that may be associated with regional angiogenesis and cellular overexpression of neurotrophin. Neuroscience. 2004; 124(3): 583591.

16. Brooks DJ. The role of the basal ganglia in motor control: Contributions from PET. J Neurol Sci. 1995; 128: 1-13.

17. Erickson KI, Boot WR, Basak C, Neider MB, Prakash RS, Voss MW, Graybiel AM, Simons, DJ, Fabiani M, Gratton G, Kramer AF. Striatal Volume Predicts Level of Video Game Skill Acquisition. Cereb Cortex. 2010; 20: 2522-2530.

18. Cools R,Clark L, Robbins TW. Differential responses in human striatum and prefrontal cortex to changes in object and rule relevance. J Neurosci. 2004; 24(5): 1129-1135.

19. Aarts E, van Holstein M, Cools R. Striatal dopamine and the interface between motivation and cognition. Front Psychol. 2011; 2: 163.

20. Obeso JA, Rodríguez-Oroz MC, Rodríguez M, Lanciego JL, Artieda J, Gonzalo N, Olanow W. Pathophysiology of the basal ganglia in Parkinson's disease. Trends Neurosci. 2000; 23(10): S8-S19.

21. Smith Y, Kieval JZ. Anatomy of the dopamine system in the basal ganglia. Trends Neurosci. 2000; 23(10): S28-S33. 
22. Draganski B, Kherif F, Kloppel S, Cook PA, Alexander DC, Parker GJ, Frackowiak RS. Evidence for segregated and integrative connectivity patterns in the human basal ganglia. J Neurosci. 2008; 28(28): 71437152.

23. Durston S, Pol H, Casey B, Giedd J, Buitelaar J, van Engeland H. Anatomical MRI of the developing human brain: what have we learned? J Am Acad Child Psy. 2009; 40: 1012-1020.

24. Toga A, Thompson P, Sowell E. Mapping brain maturation. Trends Neurosci. 2006; 29: 148-159.

25. Raz N, Rodrigue KM, Kennedy KM, Head D, Gunning-Dixon F, Acker JD. Differential aging of the human striatum: Longitudinal evidence. AJNR Am J Neuroradiol. 2003; 24(9): 1849-1856.

26. Kleim JA, Cooper NR, VandenBerg PM. Exercise induces angiogenesis but does not alter movement representations within rat motor cortex. Brain Res. 2002; 934: 1-6.

27. Black JE, Isaacs KR, Anderson BJ, Alcantara AA, Greenough WT Learning causes synaptogenesis, whereas motor activity causes angiogenesis, in cerebellar cortex of adult rats. Proc Natl Acad Sci. 1990; 87: 5568-5572.

28. Cotman CW, Berchtold NC. Exercise: a behavioral intervention to enhance brain health and plasticity. Trends Neurosci. 2002; 25(6): 295-301.

29. Lou S, Liu J, Chang H, Chen P. Hippocampal neurogenesis and gene expression depend on exercise intensity in juvenile rats. Brain Res. 2008; 1210: 48-55.

30. Ernst A, Alkass K, Bernard S, Salehpour M, Perl S, Tisdale J, Possnert G, Druid H, Frisén J. Neurogenesis in the Striatum of the Adult Human Brain. Cell. 2014; 156: 1072-1083.

31. Bergmann 0, Spalding KL, Frisén J. Adult Neurogenesis in Humans. Cold Spring Harb Perspect Biol. 2015; 7: a018994.

32. Hamzei F, Glauche V, Schwarzwald R, May A. Dynamic gray matter changes within cortex and striatum after short motor skill training are associated with their increased functional interaction. Neuroimage. 2012; 59: 3364-3372.

33. Taubert M, Draganski B, Anwander A, Müller K, Horstmann A, Villringer A, Ragert P. Dynamic properties of human brain structure: learning-related changes in cortical areas and associated fiber connections. J Neurosci. 2010; 30(35): 11670-11677.

34. Chaddock L, Erickson KI, Prakash RS, van Patter M, Voss MW, Pontifex $\mathrm{MB}, \mathrm{Kramer}$ AF. Basal ganglia volume is associated with aerobic fitness in preadolescent children. Dev Neurosci. 2010; 32(3): 249-256.

35. Eriksen BA, Eriksen CW, Effects of noise letters on the identification of a target letter in a nonsearch task. Percept Psychophys. 1974; 16: 143-149.

36. Chaddock L, Hillman CH, Pontifex MB, Johnson CR, Raine LB, Kramer
A. F. Childhood aerobic fitness predicts cognitive performance one year later. J Sport Sci. 2012; 30(5): 421-430.

37. Peters J, Dauvermann M., Mette C, Platen P, Franke J, Hinrichs T, Daum I. Voxel-based morphometry reveals an association between aerobic capacity and grey matter density in the right anterior insula. Neuroscience. 2009; 163: 1102-1108.

38. Verstynen TD, Lynch B, Miller DL, Voss MW, Prakash RS, Chaddock L, Basak C, Szabo A, Olson EA, Wojcicki TR, Fanning J, Gothe NP, McAuley E, Kramer AF, Erickson KI. Caudate nucleus volume mediates the link between cardiorespiratory fitness and cognitive flexibility in older adults. Journal Aging Res. 2012; 939285.

39. Niemann C, Godde B, Staudinger UM Voelcker-Rehage C. Exerciseinduced changes in basal ganglia volume and cognition in older adults. Neuroscience. 2014; 281: 147-163.

40. Erickson KI, Voss MW, Prakash RS, Basak C, Szabo A, Chaddock L, Kramer AF. Exercise training increases size of hippocampus and improves memory. Proc Natl Acad Sci USA. 2011; 108(7): 3017-3022.

41. Steele CJ, Penhune VB. Specific increases within global decreases: a functional magnetic resonance imaging investigation of five days of motor sequence learning. J Neurosci. 2010; 30(24): 8332-8341.

42. Doyon J, Penhune V, Ungerleider LG. Distinct contribution of the cortico-striatal and cortico-cerebellar systems to motor skill learning. Neuropsychologia. 2003; 41(3):252-262.

43. Monno A, Temprado JJ, Zanone PG, Laurent M. The interplay of attention and bimanual coordination dynamics. Acta Psychol. 2002; 110(2-3): 187-211.

44. Zatorre RJ, Fields RD, Johansen-Berg H. Plasticity in gray and white: neuroimaging changes in brain structure during learning. Nat Neurosci. 2012; 15(4): 528-536.

45. Park IS, Lee KJ, Han JW, Lee NJ, Lee WT, Park KA, Rhyu IJ. Basketball training increases striatum volume. Hum Mov Sci. 2011; 30(1): 56-62.

46. Haenggi J, Koeneke S, Bezzola L, Jäncke L. Structural neuroplasticity in the sensorimotor network of professional female ballet dancers. Hum Brain Mapp. 2010; 31(8): 1196-1206.

47. Jäncke L, Koeneke S, Hoppe A, Rominger C, Hänggi J. The architecture of the golfer's brain. PLoS One. 2009; 4(3): e4785.

48. Wei G, Luo J, Li Y. Brain structure in diving players on MR imaging studied with voxel-based morphometry. Prog Nat Sci. 2009; 19(10): 1397-1402.

49. Markham JA, Greenough WT. Experience-driven brain plasticity: beyond the synapse. Neuron Glia Biol. 2004; 1(4): 351-363.

50. Hayes SM, Hayes JP, Cadden M, Verfaellie M. A review of cardiorespiratory fitness-related neuroplasticity in the aging brain. Front Aging Neurosci. 2013; 5(31): 1-16. 